Mellanby, H. (1940). Brit. med. F. i, 682.

Mellanby, H. \& Mellanby, M. (1950). Brit. med.7. i, I34I.

Mellanby, M. (1918). Lancet, 62, 767 .

Mellanby, M. (1923). Brit. dent. F. 44, I.

Mellanby, M. (1928). Brit. dent. $¥ .49,769$.

Mellanby, M. (1934). Spec. Rep. Ser. med. Res. Coun., Lond., no. I9 г.

Mellanby, M. \& Coumoulos, H. (1944). Brit. med. $\mathscr{f} . \mathrm{i}, 837$.

Mellanby, M. \& Mellanby, H. (1948). Brit. med. $\mathcal{F}$. ii, 409.

Mellanby, M. \& Mellanby, H. (I951). Brit. med. F. i, 5 I.

Parfitt, G. J. (I954). Brit. dent. F. 97, 235.

Shaw, J. H. \& Sognnaes, R. F. (1955). In Advances in Experimental Caries Research, p. 82. [R. F. Sognnaes, editor.] Washington: American Association for the Advancement of Science.

Sobel, A. E. (1955). Ann. N.Y. Acad. Sci. 6o, 7r 3.

Sobel, A. E. \& Hanok, A. (1948). F. biol. Chem. 176, I I०3.

Sognnaes, R. F. (1947). Science, ro6, 447.

Sognnaes, R. F. (1948). F. Nutr. 36, I.

Sognnaes, R. F. \& Shaw, J. H. (1954). F. Nutr. 53, 195.

Staz, J. (1943). S. Afr. med.F. 17, I.

Steinman, R. R. \& Haley, M. I. (1957). F. dent. Res, 36, 532.

Stilwell, W. F., Edson, N. L. \& Stainton, P. V. E. (1957). The Fluoridation of Public Water Supplies. Wellington, N.Z.: Government Printer.

Toverud, G. (1949). Proc. R. Soc. Med. 42, 249.

Weinmann, J. P. \& Schour, I. (1945). Amer. F. Path. 21, 821.

Wilska, A. (1946). Odont. Tidsk. 54, 296.

\title{
Dental caries in relation to nutrition: environmental effects
}

\author{
By G. Neil Jenkins, Department of Physiology, Medical School, \\ Newcastle upon Tyne I
}

Ever since the classical work of Miller ( $189^{\circ}$ ), which demonstrated the decalcification of teeth incubated with saliva and carbohydrate foods, it has been widely believed that the acids formed from carbohydrate by mouth bacteria are the major factor in the development of caries. The local effect of sugar has been proved by the finding of Kite, Shaw \& Sognnaes (1950) that caries did not occur in susceptible animals when they received a high-sugar diet by stomach tube. It has been suggested that the initial attack on the enamel is made by proteolytic bacteria (Pincus, 1939; Gottlieb, I947) but this view became less likely when it was discovered that some of the organic matter of enamel was soluble in acid (Stack, I955) and could therefore be removed without proteolysis. A compromise theory suggests that the breakdown products of proteolytic action remove the calcium salts by forming complexes at neutral or even alkaline $\mathrm{pH}$ (Atkinson \& Matthews, 1949). A similar concept has recently been developed by Schatz and his colleagues in what they call the 'proteolytic-chelation' theory (Schatz, Karlson, Martin \& Schatz, I957). They emphasize that proteolysis, and the metabolism of many substances, may result in the formation of complexing agents, and suggest that the formation of such substances by salivary organisms from the organic matter of the teeth could lead to decalcification without acid. Lura (1957) has suggested in addition that food and salivary constituents might be the precursors of complexing substances. These 
stimulating suggestions have not yet been fully assimilated into current thinking on the caries problem but, if future work indicates that a significant proportion of the decalcification of a carious tooth is brought about by complexing agents rather than by hydrogen ions, the main ideas in this paper will need revision. The controversy refers mainly to the initial attack on enamel-it is obvious that acids alone could not account for caries in dentine because, like bone, this tissue retains its shape intact after decalcification.

\section{$p H$ changes in the vicinity of the tooth}

The work of Stephan (1940), fully confirmed by others, has shown that after the mouth is rinsed with a glucose or sucrose solution the dental 'plaque', i.e. the layer of mucin, bacteria and food debris which forms on the tooth surface, may fall in $\mathrm{pH}$ from 7.0 to about 5.0 within a few minutes and may take up to an hour to return to normal. The most striking results are found in subjects who have abstained from brushing their teeth for several days. Stephan studied mainly plaques on the smooth surfaces of the anterior teeth, although caries rarely begins here but usually in the depths of occlusal fissures, at the contact points between adjacent teeth, or at the margins of the gums. At these sites, the plaque is difficult to remove by most toothbrushes and saliva cannot readily permeate. It is usually assumed that the $\mathrm{pH}$ changes in these areas, even after tooth brushing, resemble those on the smooth surfaces after a plaque has been undisturbed for several days.

These somewhat academic observations have now been extended to the study of the effects of foods, as opposed to sugar rinses (Ludwig \& Bibby, 1957), and to the contact points (Jenkins \& Kleinberg, I956). The former workers measured in vitro the $\mathrm{pH}$ of pieces of plaque removed at different times after eating; the latter determined the $\mathrm{pH}$ undisturbed in the contact points, but their results agree in showing that the 'Stephan curve' is found with most foods and at the contact points. The only differences noted were, first, that while foods were taken the fall in $\mathrm{pH}$ tended to be slower than with a sugar rinse probably because highly buffered saliva is stimulated more vigorously by eating than by the rinse and, secondly, if starchy foods adhered to the plaque for long periods then the $\mathrm{pH}$ remained at its minimum for longer than the few minutes found with sugar rinses, even up to several hours in some subjects.

The retention of foods has been studied quantitatively by Bibby, Goldberg \& Chen (195I) with methods whose validity was carefully established. They compared the amounts of ninety-six foods retained on the teeth by removing, either by a tooth brush or an atomizer, the residues present immediately after eating and estimating their carbohydrate contents. Their findings confirm subjective impressions that starchy foods are retained, and they also observed that high fat or salt concentrations in a food tended to reduce retention. Their method leaves out of account, however, the time during which a food is retained. For example, they found almost twice as much carbohydrate retention from chocolate as from white bread, but the soluble chocolate has been found to be removed more quickly than slowly digested starch (Lanke, 1957). The duration of the low $\mathrm{pH}$ conditions depends on the time during 
which the food is present; the amount retained is probably much less important since a maximal acid production occurs with quite low concentrations ( $\equiv 5 \%$ glucose or below).

\section{The relationship between plaque $p H$ and the decalcification of the enamel}

The concentrations of calcium and phosphate ions in saliva are such that at neutrality it is saturated with calcium phosphate and, at least under test-tube conditions, the enamel has been found to be insoluble in it (Fosdick \& Starke, r939). As already mentioned, if complexing agents are present or can be formed in the plaque, then enamel may dissolve at neutrality but this has not yet been observed. As the $\mathrm{pH}$ falls, a point is reached at which the ionic concentrations are no longer able to prevent the enamel from dissolving. This critical $\mathrm{pH}$ varies in individuals, depending mainly, of course, on their salivary concentration of $\mathrm{Ca}$ and $\mathrm{P}$, but is usually stated to be between $5^{\circ} \mathrm{O}$ and 5.5 . It must be admitted that this concept has been worked out on the assumption that the enamel surface is in equilibrium with saliva. In fact, conditions on the inner surface of the plaque presumably control the amount of enamel dissolving and there is little information on this point. Circumstantial evidence supporting the concept of the critical $\mathrm{pH}$ is the finding by Englander, Carter \& Fosdick (1956) that in fifty-one caries-free subjects the plaque $\mathrm{pH}$ never fell below 5.4 after sugar rinses, whereas $57 \%$ of their readings in ror caries-active subjects were below this figure.

\section{Dietary influences on acid decalcification}

How may diet affect these events? Theoretically, if the calcium or phosphate concentrations of saliva-and therefore presumably of the plaque-were raised, then the critical $\mathrm{pH}$ would be expected to fall. Unfortunately, salivary calcium does not appear to be influenced significantly by dietary intake (Jonsgar, r937) and only small effects have been reported with physiological changes of phosphate intake (Gurney \& Huschart, I95०; Bates, 1958). It has also been suggested (Eddy, Heft, Rosenstock \& Ralston, I933) that a high carbohydrate intake, which lowers blood phosphate, may also lower salivary phosphate and thus be an additional way in which carbohydrate may favour caries, but Bates (1958) could not confirm this observation. Many experiments in this field have been invalidated because it has not always been realized that the composition of saliva depends on its rate of flow (e.g. salivary phosphate falls with increased rate of flow).

It seems reasonable to suppose that foods which contain soluble calcium or phosphate might protect the tooth, and experiments with animals have shown that the addition of sodium phosphate to a caries-producing diet reduces its effect (Wynn, Haldi, Bentley \& Law, 1956), but evidence on human caries is lacking.

Influence of saliva. A factor which can, to some extent, be influenced by diet is the rate of flow and buffering power of saliva. Its importance in caries can be inferred from several groups of findings. First, several reports state that caries-free individuals have a higher average rate of flow than comparable caries-active subjects (for references see Jenkins, $195^{6}$ ) and it has also been found that the more rapid the flow 
the higher is the $\mathrm{pH}$ and buffering power (Ericsson, 1949). Secondly, the $\mathrm{pH}$ fall after carbohydrate tends to be smaller in the mandibular incisors (close to the submaxillary ducts) than in the maxillary incisors (relatively inaccessible to saliva) (Jenkins \& Kleinberg, 1957). Thirdly, in one subject, in which retention of starchy food was especially marked and the plaque $\mathrm{pH}$ remained low for long periods after meals, the eating of a sweet (accompanied by a profuse salivary flow) while the starch was still on the plaque and the $\mathrm{pH}$ was low caused a temporary rise in $\mathrm{pH}$ (Jenkins \& Kleinberg, 1956).

There is little doubt that salivary flow is largely controlled by inborn factors, but tough foods and a habit of vigorous mastication will make it more likely that an individual secretes near his maximum rate and with the highest possible buffering power.

The relative importance of starch and sugar. Emphasis has often been placed on the importance of sugar in caries and starchy foods have often been thought to be less important. This belief has perhaps been encouraged by a superficial interpretation of two recent lines of work. The very thorough experiment carried out at Vipeholm, Sweden for 5 years on 436 mental patients has proved beyond doubt that sugar taken between meals increases caries, especially if given in a sticky form (Gustafsson, Quensel, Lanke, Lundqvist, Grahnén, Bonow \& Krasse, 1954). Supplements of even up to $300 \mathrm{~g}$ sucrose taken with meals, either in solution or incorporated in foods, had no significant effect on caries-a conclusion later confirmed by the Medical Research Council experiment on schoolchildren (King, Mellanby, Stones \& Green, I955). This effect can be readily explained on the basis of Stephan curves, since each helping of carbohydrate between meals would be expected in most subjects to produce a $\mathrm{pH}$ fall similar to that after a meal. The number of times carbohydrate is taken will be related to the number of times the plaque approaches or reaches the critical $\mathrm{pH}$. In the control group of the Vipeholm study, which received no sugar between meals and very little with meals, the caries rate was virtually nil. Although this finding might suggest that sugar was essential for caries this conclusion would not be justified for two reasons. First, in addition to a low sugar intake, total carbohydrate was reduced to $130 \mathrm{~g}$ and, secondly, the calories were made up with $15^{\circ} \mathrm{g}$ margarine daily (giving a total of $225 \mathrm{~g}$ fat). This group really tested the effect of a diet low in sugar and total carbohydrate and high in fat and therefore gives little information about the effect of low sugar intake alone. Unfortunately, the influence of bread on caries was outside the terms of reference of this experiment. It would have been extremely interesting to have tested the effects of some starchy foods taken between meals and, until it is done, it is impossible to decide finally on the relative importance of sugar and starch as promoters of caries.

The other evidence tending to support the view that starch is less harmful is the observation that to produce caries readily in experimental animals, sugar must be present in the diet. Starch and dextrin have smaller effects (Shaw, 1957). The diets of the animals contained uncooked starch, however, and its physical properties are so different from the starch in human foods that the comparison seems invalid, 
The position may be summarized as follows: studies of plaque $\mathrm{pH}$ show that starchy foods produce a $\mathrm{pH}$ minimum similar to that produced by sugars and, in fact, often more prolonged, but no experiments on human caries have been carried out in which the effects of starch and sugar have been directly compared, and animal experiments are indecisive on this point.

Local effects of fluoride. In the preceding paper, Hartles \& Slack (1959) have discussed the possibility that fluoride reduces or postpones caries by lowering the solubility of enamel. In assessing the other possible mechanism, namely that fluoride acts as an enzyme poison, two pieces of information are necessary: first, we must know the concentration of fluoride in the plaque and secondly the minimum concentration that can exert a significant effect on plaque bacteria. Neither is known with certainty. If fluoride is added to saliva and glucose mixtures and the $\mathrm{pH}$ measured during incubation, it is found that about I p.p.m. is needed to produce the smallest detectable reduction in the fall in $\mathrm{pH}$ (Wright \& Jenkins, 1954), but much higher levels (say io p.p.m.) are required to exert an effect likely to be significant in caries. It has been found that if fluoride is added to saliva after the $\mathrm{pH}$ has already fallen to about $5^{\circ} \circ$ the bacteria are much more sensitive to it. Under these conditions, Io p.p.m. or even less completely prevent any further acid production (Jenkins, I958a).

The fluoride of the plaque might arise from two sources, either from drinks such as water and tea (in which event the concentration in the plaque would not be expected to rise above that of the drink, i.e. about $\mathbf{I}-2$ p.p.m., unless the plaque can concentrate it) or from the enamel surface which is known to have a fluoride concentration between five and ten times that of enamel as a whole (Jenkins \& Speirs, I953; Brudevold, Gardner \& Smith, I956). It seems possible that as the plaque $\mathrm{pH}$ falls, parts of the extreme outer layer of the enamel may dissolve and release into the plaque fluoride at a concentration that might arrest further acid production. This process would only occur under the acid conditions which would favour the inhibitory action. It is realized that the limiting factor in this process is the solubility of calcium fluoride in acidified plaque in the presence of a high calcium concentration, and too little is known about it to justify dogmatic statements. When the plaque $\mathrm{pH}$ rises, the fluoride would probably become re-attached to the enamel surface.

Another possibility may be briefly mentioned. Fluoride is known to inhibit enolase, which converts phosphoglyceric into phosphopyruvic acid. If a plaque were poisoned with fluoride it might be expected that phosphoglycerate would accumulate at the expense of lactate, the normal end-product. Incidentally, since the dissociation constants of phosphoglyceric and lactic acids are similar, a fluoride inhibition might be present without much alteration of the $\mathrm{pH}$; in other words, $\mathrm{pH}$ changes are not necessarily the best way of detecting fluoride action. Now, I have shown that traces of phosphoglycerate (like other organic phosphates) reduce the effectiveness of lactic acid in dissolving teeth (Jenkins, I957) and its accumulation in plaque might well explain a reduction in caries. However, it has not yet been possible to detect the presence of phosphoglycerate in plaque or saliva treated with low concentrations of fluoride. 
Protective factors in unrefined foods. It has often been suspected that highly refined carbohydrates are more prone to give caries than unrefined sugars and flour (Osborn, Noriskin \& Staz, I937), but there appears to be no valid statistical evidence on this point. The observations of Osborn et al. that these unrefined foods reduced the decalcification of teeth when incubated with saliva, has been confirmed for crude cane juice, black treacle and high-extraction flours although no protective effect was observed with various brown sugars and honey (Jenkins, Forster, Speirs \& Kleinberg, I959). The results with flours were not entirely consistent but the other two materials had quite dramatic effects. A number of constituents seem to be involved and it is not easy to judge their relative importance. However, the buffers in treacle and cane juice, the calcium in treacle and the organic phosphates (such as phytate) in brown flour and treacle, as well as unknown substances, probably contribute (Jenkins, 1958b).

In addition to chemical protection, Lanke (1957) has shown quantitatively that unrefined flours are cleared from the mouth more rapidly than are refined. Experiments on animals in which the caries incidences on diets containing crude and refined carbohydrates have been compared have led to contradictory results, but some striking reductions in the presence of unrefined foods have been reported (Taketa \& Phillips, I957; Shaw, 1957). Although the effectiveness of unrefined foods as a protection against caries will remain problematical until adequate clinical experiments have been carried out, the test-tube experiments suggest that it is worthy of further study, along with the possibility of 'fortifying' refined carbohydrates with protective substances.

\section{REFERENCES}

Atkinson, H. F. \& Matthews, E. (1949). Brit. dent. J. 86, 167.

Bates, J. F. (1958). F. dent. Res. 37, 755.

Bibby, B. G., Goldberg, H. J. V. \& Chen, E. (r95 I). F. Amer. dent. Ass. 42, 49 I.

Brudevold, F., Gardner, D. E. \& Smith, F. A. (1956). F. dent. Res. 35, 420.

Eddy, W. H., Heft, H. L., Rosenstock, S. \& Ralston, R. (1933). F. dent. Res. r3, 5 I I.

Englander, H. R., Carter, W. J. \& Fosdick, L. S. (r956). F. dent. Res. 35, 792.

Ericsson, Y. (1949). Acta odont. scand. 8, Suppl. 3 .

Fosdick, L. S. \& Starke, A. C. (1939). F. dent. Res. 18, 417.

Gottlieb, B. (1947). Dental Caries. Philadelphia: Lea and Febiger.

Gurney, B. F. \& Huschart, J. H. (I950). J. dent. Res. 29, 63.

Gustafsson, B. E. (1954). Acta odont. scand. II, 207.

Gustafsson, B. E., Quensel, C.-E., Lanke, L. S., Lundqvist, C., Grahnén, H., Bonow, B. E. \& Krasse, B. (1954). A cta adont. scand. rr, 232.

Jenkins, G. N. ( 1956). Brit. dent. F. I01, 79.

Jenkins, G. N. (1957). Odont. Revy, 8, 68.

Jenkins, G. N. (1958a). Brit. dent. $\mathscr{~}$. ro4, 54 .

Jenkins, G. N. (1958b). \%. dent. Res. 37, 759 .

Jenkins, G. N., Forster, M. G., Speirs, R. L. \& Kleinberg, I. (1959). Brit. dent. F. (In the Press.)

Jenkins, G. N. \& Kleinberg, I. (1956). F. dent. Res. 35, 964 .

Jenkins, G. N. \& Kleinberg, I. (1957). F. dent. Res. 36, 8r6.

Jenkins, G. N. \& Speirs, R. L. (1953). F. Physiol. I21, 2 I $P$.

Jonsgar, S. (1937). Y. dent. Res. 16, 173.

Hartles, R. L. \& Slack, G. L. (1959). Proc. Nutr. Soc. $\mathbf{8 8 , 7 9 .}$

King, J. D., Mellanby, M., Stones, H. H. \& Green, H. N. (1955). Spec. Rep. Ser. med. Res. Coun., Lond., no. 288 .

Kite, O. W., Shaw, J. H. \& Sognnaes, R. F. (1950). F. Nutr. 42, 89.

Kleinberg, I. (1958). 7. dent. Res. 37, $75^{6}$. 
Lanke, L. S. (1957). Acta odont. scand. 15, Suppl. 23.

Ludwig, T. G. \& Bibby, B. G. (1957). F. dent. Res. 36, 56 .

Lura, H. E. (1957). Odont. Revy, 8, I69.

Miller, W. D. (1890). The Microorganisms of the Human Mouth. Philadelphia: S. S. White.

Osborn, T. W. B., Noriskin, J. N. \& Staz, J. (1937). F. dent. Res. 16, I65.

Pincus, P. (1939). Dent. Rec. 59, 615.

Schatz, A., Karlson, K. E., Martin, J. J. \& Schatz, V. (1957). Odont. Revy, 8, 154.

Schatz, A. \& Martin, J. J. (1958). Ann. Dentist. 17, I.

Shaw, J. P. (1957). F. Amer. dent. Ass. 55, 785

Stack, M. V. (1955). Ann. N.Y. Acad. Sci. 60, 585 .

Stephan, R. M. (1940). F. Amer. dent. Ass. 27, 718.

Taketa, F. \& Phillips, P. H. (I957). Fed. Proc. 16, 399.

Wright, D. E. \& Jenkins, G. N. (1954). Brit. dent. F. 96, 30.

Wynn, W., Haldi, J., Bentley, K. D. \& Law, M. L. (1956). F. Nutr. 58, 325.

\title{
A combined attack upon a common problem
}

\author{
By A. M. Horsneld, Dental School, The London Hospital Medical College, University
} of London, and Ella ScotT, Dietetic Department, The London Hospital, London, E. I

This paper allows an opportunity to put on record certain facts which have led to the present co-operation between the Department of Children's Dentistry and the Department of Dietetics, and though it is not possible at the present time to draw any definite conclusions from these facts, it may be reasonable to make some observations concerning the results obtained so far.

The problem was and still is the large number of young children mostly between the ages of 2 and 5 years with gross caries, who are referred to the Dental Department for help, by either their family doctor or family dentist. Our efforts to do something positive about the problem which these children present really began only a few years ago, as it was not until I95 I that a Department of Children's Dentistry was established as a separate unit within the Dental Department and School. In this special section, six sessions each week are set aside for the prevention and treatment of dental caries. Children who are brought to the Department for the relief of pain could of course be treated by the extraction of the offending tooth. This is the traditional method and no doubt at the special moment could be considered to be effective and satisfactory.

Treatment by extraction, however, means the infliction of further trauma to relieve a local condition. This further trauma has a long-term effect and without question has a direct bearing on the attitude of members of the public towards dentistry and to their dental and general health.

In this dental school we are convinced that the primary teeth are of importance and we cannot subscribe to the popular names, such as baby or temporary teeth, which are given to them. A tooth which can serve the patient well for 7 or 8 years during such an important period of growth and development as ages 2 to 8 can hardly deserve to be named temporary. In fact, during this period the foundations for nearly all the good and bad habits of the individual's life are being laid down. Just so will 